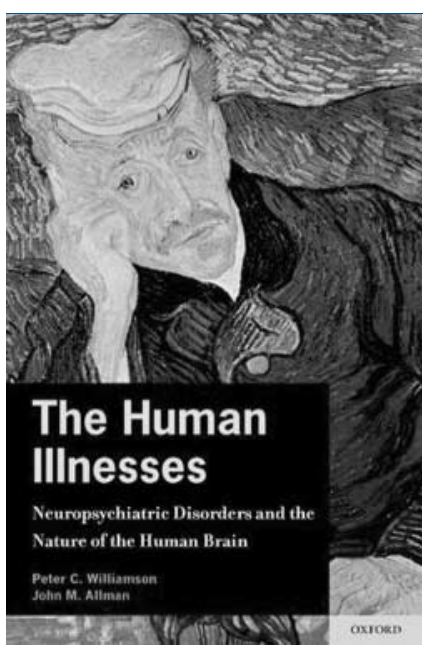

\section{The Human Illnesses:} Neuropsychiatric Disorders and the Nature of the Human Brain

By Peter Williamson \& John Allman. Oxford University Press USA. 2011 £45.00 (hb). 304 pp.

ISBN: 9870195368567

This publication is born from a collaboration between a neuropsychiatrist and evolutionary biologist. It starts from the premise that naturally occurring animal equivalents of some psychiatric disorders such as depression and simple phobia can be found in many species, but more complex disorders such as schizophrenia, autism and frontotemporal dementias appear as uniquely human illnesses. Their thesis is that the neuronal pathways that underlie these neuropsychiatric conditions mirror unique human capabilities. Determining how these capabilities are represented in the human brain may not only tell us about what makes the human brain human but also provide a framework for understanding neuropsychiatric disorders in a new way.

The book has a broad scope, covering some background neuroscience and details of a number of specific illnesses, including schizophrenia, bipolar disorders, autism, attentiondeficit hyperactivity disorder and temporal dementia, and then speaking directly to the nature of some potentially unique human neural systems such as self-monitoring, language systems and systems for effective processing and social integration. It closes striving to draw these strands together to ask why humans experience these disorders and looking to the future in terms of implications.

The authors themselves acknowledge that the task of describing such disorders, with a diverse and complicated literature, is a daunting one and it would be beyond their expertise to be comprehensive in all the fields touched upon. The writing itself has a rather dry, and for my taste, rather sterile tone but it is clear and it is able to focus on an argument and follow its thread. It also manages to engage in reasonably fine detail, for example the potential role of HAR1F in regulating cortical development or the FOXP2 gene potentially underpinning human developmental language abnormalities.

The problem with this book though is that it falls between two stools. The ideas presented are not in any way new, only attractively arranged and brought together, and I suspect it lacks the depth of understanding to satisfy the expert, yet is perhaps overly rich in information for the student. The appropriate target is perhaps the clinician with a casual interest; still, it is a little too dry to be a 'bedtime book', compared with for example, Zeman's Consciousness: A User's Guide (Yale University Press, 2002). In some ways this lack of an obvious home is a disappointment as it is a book that has much to offer. This conundrum does to a certain extent beg the question of what is the purpose of a textbook in modern medicine. Although they still work admirably as a distillation of expert knowledge for those in training, the role of the monograph as an exploration of ideas is less certain. One hopes they can still find readership, but with the ease of access provided by the digital era one fears this may not be the case.

Alan Carson Consultant Neuropsychiatrist, Robert Fergusson Unit, Royal Edinburgh Hospital, Morningside Terrace, Edinburgh EH10 5HF, UK. Email: alan.carson@|pct.scot.nhs.uk

doi: 10.1192/bjp.bp.111.094722

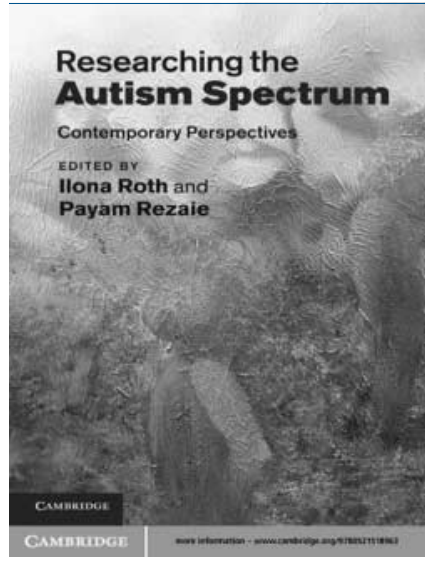

\section{Researching the Autism Spectrum: Contemporary Perspectives}

Edited by Ilona Roth \& Payam Rezaie. Cambridge University Press. 2011. £35.00 (pb). 408 pp. ISBN: 9780521736862

Autism research is a rapidly developing field, spanning a wide range of enquiry, from classification, to genetics, to cognition and development. In parallel, evidence-based guidelines have attempted to keep up, and have revealed the nature and extent of the evidence gaps that need to be filled if we are ever going to satisfactorily address the needs of patients and families who are impaired by this prototypical neurodevelopmental condition. It is timely, therefore, that Roth and Rezaie have brought together accounts by eminent international academics to describe the range and achievements of current autism research. How successful have they been?

The first thing to note is that this book is very thorough in its range of coverage of different research themes. I learnt much that was new to me. For example, the chapter on magnetoencephalography (MEG) as a tool to investigate the neurophysiology of autism provides a mass of informative detail explaining this complex technology and its clinical applications, such as the important area of epileptiform activity. Equally, new detail was provided for psychological as well as for physical enquiry, in the description of research findings into the role of memory in autism. In this regard, the editors have successfully addressed their aim of redressing 'uneven and patchy coverage' of research areas that have a history of 'conceptual and methodological difficulties'.

I also found the book useful in its consolidation of more wellknown areas of enquiry, such as its overview of the genetics of autism and its explanation of 'hot' areas of current research into such issues as serotonin, reelin and oxytocin function.

On finishing this comprehensive overview, I wondered whether it might have been possible for the editors, in a final chapter, to have predicted what current autism research might lead to, in terms of clinical practice, over the next generation. Will there be ways of attenuating autism, by early intervention, through biochemical and/or psychoeducational means? With the pace of development over the preceding generation, admirably covered by these researchers, this is a truly fascinating thought.

Iain Mcclure Consultant Child and Adolescent Psychiatrist, Royal Hospital for Sick Children, 9 Sciennes Road, Edinburgh EH9 1LF, UK. Email: imcclure@nhs.net

doi: 10.1192/bjp.bp.111.099309 